\title{
The rationale for CBME and early impressions
}

\author{
Kash Visram, MD \\ Queen's University, Kingston, ON, Canada
}

Cite as: Can Urol Assoc J 2018;12(6):155. http://dx.doi.org/10.5489/cuai.5422

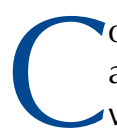

ompetency-based medical education (CBME) represents a pivotal change to postgraduate medical training and will be implemented for all new urology trainees across Canada in July 2018. At Queen's University, all postgraduate specialty residency programs fully transitioned to CBME in July 2017. As the first urology resident to be trained under the CBME model, I hope to explain CBME and the rationale for it, and provide commentary on initial experiences.

Traditionally, residency has been centred around a timebased model that presumed sufficient experience would be accrued over the course of one's training to develop the skills and knowledge required to practice independently. Assessment of this model suggests that it is failing to adequately prepare physicians for contemporary practice. ${ }^{1}$

CBME shifts the focus from a time-based model to a competency-based model. Acknowledging the desired capabilities in fully trained physicians, the curriculum is developed from the outwards in, noting the required skills that an independent practitioner should have and identifying training experiences and establishing a teaching syllabus required to develop them. ${ }^{2}$ This approach is learner-centred and focused around creating physicians that are best able to meet the healthcare needs of the populations they serve. ${ }^{3}$

Under CBME, residents undergo four broad stages of training: transitions to discipline, foundations of discipline, core discipline, and transitions to practice. Each of these stages contains specific entrustable professional activities (EPAs) — important routine care activities that define a specialty. Progression towards and achievement of competence for an EPA is monitored through frequent and ongoing assessment. Once a trainee has achieved all the EPAs, it objectively demonstrates that they have obtained all the skills necessary to practice urology independently.

Initiation of CBME at Queen's was met with both excitement and trepidation. Moving from a system of infrequent evaluation of residents, typically once or twice per block, to task-specific frequent evaluation was practically challenging. Developing software that was user-friendly and easy to access required trial and error. Further, determining the number of evaluations needed, identifying whom these evaluations should come from, and establishing a clear definition of competence were all new frontiers that CBME forced us to explore. Hesitations around the effect of CBME residents training alongside traditional residents was seen as a possible source of conflict, but did not seem to effect the quality of training, as perceived by residents from either cohort. From a trainee perspective, the frequency of evaluation improved the quality of feedback, as discussions centred around identification of strengths and weaknesses pertaining to a skill, and clear and concise takeaways on how to improve.

As data from CBME is generated, it will provide insights into the success of CBME as a training model. Through CBME, we can conduct deep exploration of the relationship between experience and skill acquisition in urology, identify high-quality experiences for trainees that are impactful on skill development, and develop metrics that measure our successes and failures within the CBME. Ongoing nurturing of CBME during its infancy is essential to ensure implementation of processes that enhances the competencybased model.

\section{References}

1. Frenk J, Chen L, Bhutta ZA, et al. Health professionals for a new century: Transforming education to strengthen health systems in an interdependent world. Lancet 2010;376:1923-58. https://doi.org/10.1016/S0140-6736(10)61854-5

2. Boucher A, Frank J, Van Melle, E, et al. Competency-based medical education: A white paper commissioned by the AFMC Board of Directors. 2017.

3. Lobst WF, Sherbino J, Cate 0T, et al. Competency-based medical education in postgraduate medical education. Med Teach 2010;32:651-6. https://doi.org/10.3109/0142159X.2010.500709

Correspondence: Dr. Kash Visram, Queen's University, Kingston, 0N, Canada; kvisram@qmed.ca 